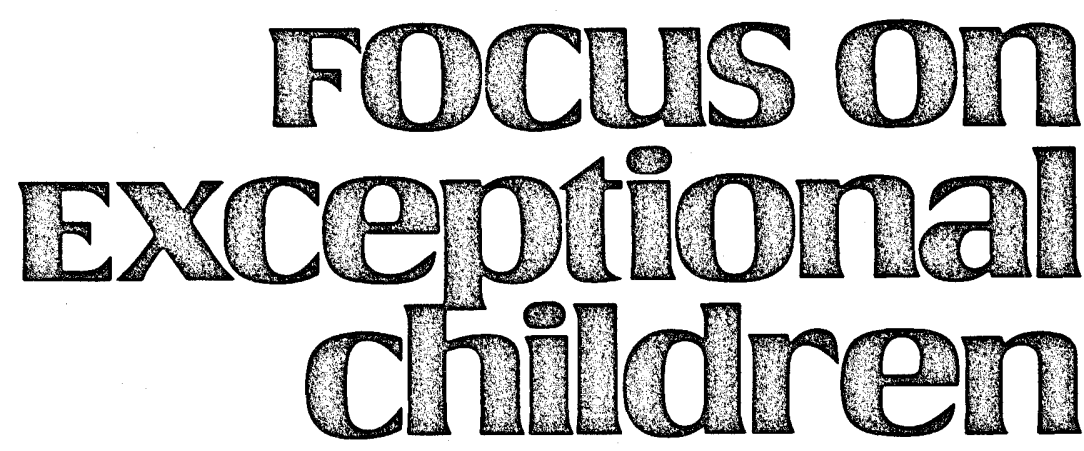

\title{
Depression in Children and Adolescents: Identification, Assessment, and Treatment
}

John W. Maag and Steven R. Forness

Depression in children and adolescents is a mood (affective) disorder whose magnitude and clinical importance has only recently permeated the concern of educators. Once considered exclusively the domain of psychiatrists, depression can and should be considered by school personnel in identification, assessment, and treatment (Reynolds, 1984). Unfortunately, professionals in special education have been slow to recognize that depression affects a wide range of school-related functioning (Maag \& Rutherford, 1987, 1988). A survey by 47 nationally recognized experts in education of the behaviorally disordered, for instance, did not even mention depression as an important research issue in the field (Epstein \& Cullinan, 1984). Youngsters with behavioral disorders are not the only handicapped group at risk for developing depression. Depression has been identified in children and adolescents with mild mental retardation, learning disabilities, and speech and language disorders (e.g., Cantwell \& Baker, 1982; Reynolds \& Miller, 1985; Stevenson \& Romney, 1984).

Depression may be overlooked as a potentially important area of concern in special education, in part, because of its colloquial presence and associated ambiguity (Kendall, Hollon, Beck, Hammen, \& Ingram, 1987). At one end of the spectrum, depression is a commonly used term to denote "feeling a little bummed out." At the other end of the spectrum, depression refers to a clinical syndrome or disorder. Kazdin (1990) provides the following distinction:

As a symptom, depression refers to sad affect and as such is a common experience of everyday life.

As a syndrome or disorder, depression refers to a group of symptoms that go together. Sadness may be part of a larger set of problems that include the loss of interest in activities, feelings of worthlessness, sleep disturbances, changes in appetite and others. (p. 121)

These distinctions are more than a matter of semantics-different definitions and uses of the label "depression" have important implications (Kendall et al., 1987). The syndrome of depression can be present, in secondary ways, in other disorders. For example, a schizophrenic individual may manifest depressive symptomatology without meeting diagnostic criteria for major mood disorder (American Psychiatric Association, 1987).

In this article we are providing only a brief overview of the current status of knowledge in the area of child and adolescent depression. For in-depth reviews, see Dolgan (1990), Kazdin (1990), and Reynolds (1985). We describe diagnostic criteria and identification procedures as well as assessment methodology and intervention strategies. The focus is on depression in handicapped populations in school settings and the implications for special educators. 


\section{CURRENT PERSPECTIVES}

For many years, controversy has surrounded the nature of depression in children and adolescents (Kaslow \& Rehm, 1991). For example, conventional psychoanalytic doctrine postulates that depression cannot exist until the onset of adolescence and the development of the superego (Rie, 1966; Rochlin, 1959). A popular view during the 1970s reflected the belief that depression in children was "masked" and must be inferred from underlying behaviors such as hyperactivity, aggression, irritability, delinquency, and poor school performance, to name a few (e.g., Cytryn \& McKnew, 1974; Malmquist, 1977). Lefkowitz and Burton (1978) suggested that depression represents a transitory developmental phenomenon which abates spontaneously without intervention; and Seifer, Nurcombe, Scioli, and Grapentine (1989) currently suggest that depression is but one symptom usually found in a pattern of other symptoms that seem to cluster together in children.

The current consensus among researchers and clinicians, however, is that depression in children and adolescents

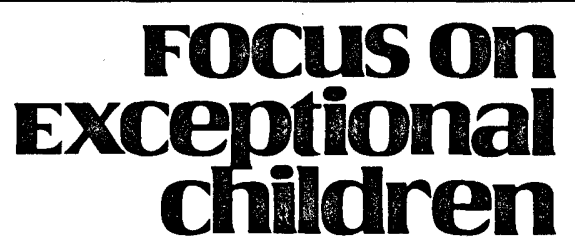

ISSN 0015-511X FOCUS ON EXCEPTIONAL CHILDREN (USPS 203-360) is published monthly except June, July, and August as a service to teachers, special educators, curriculum specialists, administrators, and those concerned with the special education of exceptional children. This publication is annotated and indexed by the ERIC Clearinghouse on Handicapped and Gifted Children for publication in the monthly Current Index to Journals in Education (CIJE) and the quarterly index, Exceptional Children Education Resources (ECER). It is also available in microfilm from Xerox University Microfilms, Ann Arbor, MI. Subscription rates: Individual, \$27 per year; institutions, $\$ 36$ per year. Copyright (C) 1991, Love Publishing Company. All rights reserved. Reproduction in whole or part without written permission is prohibited. Printed in the United States of America. Second class postage is paid at Denver, Colorado. POSTMASTER: Send address changes to:

Love Publishing Company

Executive and Editorial Office

1777 South Bellaire Street

Denver, Colorado 80222

Telephone (303) 757-2579
Edward L. Meyen

University of Kansas

\section{Glenn A. Vergason} Georgia State University

Richard J. Whelan

University of Kansas Medical Center
Holly Rumpler
Senior Editor

Stanley F. Love

Publisher parallels that found in adults. Consequently, the diagnostic criteria for diagnosis of depression in adults also is appropriate and applicable to children and adolescents (Carlson \& Cantwell, 1980; Chambers et al., 1985; Chiles, Miller, \& Cox, 1980; Kashani, Barbero, \& Bolander, 1981; Mitchell, McCauley, Burke, \& Moss, 1988).

\section{Diagnostic Criteria}

The primary diagnostic system that researchers and clinicians currently use is the Diagnostic and Statistical Manual for Mental Disorders-Revised (DSM-III-R) (American Psychiatric Association, 1987). The DSM-III-R criteria for all mood disorders in adulthood, including depression, are applied to children as well. Although depression is a clinical condition that can be diagnosed in children, adolescents, and adults, its specific symptoms, associated features, and clinical course can vary as a function of development (Kazdin, 1990). DSM-III-R provides a standardized nomenclature, but this system does not help to identify developmental differences. Cicchetti and Schneider-Rosen (1986) have suggested that depression becomes a problem when it interferes with social, cognitive, or emotional competencies

\section{DSM-III-R Criteria for Major Depressive Disorder}

At least five of the following symptoms must be present during the same 2-week period; at least one of the symptoms is either

(1) depressed mood, or (2) loss of interest or pleasure.

- Depressed mood most of the day, nearly every day (either by subjective account; e.g., feels "down" or "low" or is observed by others to look sad or depressed)

- Loss of interest or pleasure in all or almost all activities nearly every day (either by subjective account or is observed by others to be apathetic)

- Significant weight loss or weight gain (when not dieting or binge-eating) (e.g., more than $5 \%$ of body weight in a month) or decrease or increase in appetite nearly every day (in children consider failure to make expected weight gains)

- Insomnia or hypersomnia nearly every day

- Psychomotor agitation or retardation nearly every day (observable by others, not merely subjective feelings of restlessness or being slowed down) (in children under 6 , hypoactivity)

- Fatigue or loss of energy nearly every day

- Feelings of worthlessness or excessive or inappropriate guilt (either may be delusional) nearly every day (not merely selfreproach or guilt about being sick)

- Diminished ability to think or concentrate, or indecisiveness nearly every day (either by subjective account or observed by others)

- Thoughts that he or she would be better off dead or suicidal ideation, nearly every day; or suicide attempt 
necessary for the successful resolution of developmental tasks. A developmental perspective complements DSM-III-R criteria by providing a broader framework for understanding the nature of depression in children and adolescents (Carlson \& Garber, 1986).

Depressive symptoms may be included in other types of disorders. Separation anxiety disorder, adjustment disorder with depressed mood, and uncomplicated bereavement are conditions associated with depressive symptoms such as sadness and loss of interest in usual activities. Severity, duration, and precipitants of the symptoms are major determinants of the type of depressive disorders diagnosed (Kazdin, 1990). A scheme depicting a continuum of mood disorders and selected differential problems is presented in Table 1.

\section{TABLE 1}

\section{Classification Scheme for Mood Disturbances}

\section{Pathology}

Severe

Single episode*
Recurrent $^{\star \star}$

Moderate

Mild

$$
\text { Dysthymia }^{\star \star *}
$$

Atypical depression

Adjustment disorder: Depressed mood Withdrawal

Differential

Schizophrenia Schizoaffective disorder Separation anxiety

Nonpathological

Demoralization

Bereavement

*Estimates are that more than $50 \%$ of individuals having a first single episode will eventually have recurrent episodes.

**Major depression, recurrent, may predispose to development of bipolar disorder.

${ }^{\star \star \star}$ Dysthymia and cyclothymia may predispose to development of a major mood disorder.

Distinctions should be made between depression and dysthymia. The latter is seen as relatively less severe but recurring over a longer period, often punctuated by periods of normal mood that may last for days or even weeks. Another important distinction is between unipolar and bipolar depressive disorders. Unipolar depressive disorders consist of continuous or intermittent periods of dysphoric mood or anhedonia (inability to have fun), whereas bipolar disorders involve alternating episodes of depression and inappropriate euphoria, excessive energy, grandiosity, impulsivity, and poor judgment (Rizzo \& Zabel, 1988). Common conditions of both differential pathological and nonpathological origin are noted in Table 1 as well; the former are those of similar severity but different pathological nature, and the latter are within the range of normal emotional responses.

Little is known about manic conditions in children, as they are believed to be rare and difficult to diagnosis in this age group (Kovacs, 1989). Criteria for major depressive disorder and dysthymia generally are necessary in the diagnosis of bipolar disorder and cyclothymia, respectively, along with specific criteria for alternating manic features. It is interesting to speculate whether the episodic nature of a bipolar disorder could render an afflicted child ineligible for special education in that he or she would fail to meet consistently the criterion of a "pervasive mood of sadness or depression" even though bipolar disorder is possibly more debilitating than depression per se (Forness, 1988).

\section{Subtypes of Childhood and Adolescent Depression}

The classification scheme illustrated in Table 1 represents a continuum of mood disorders, from the DSM-III-R, that may be present in children and adolescents. Childhood depression can further be classified into several distinct subtypes, each positing a slightly different etiological base and, therefore, having implications for identification, assessment, and treatment (Maag \& Rutherford, 1988). Different subtypes of depression are presented in Table 2.

Several important distinctions exist between each subtype. Anaclitic depression, also termed the "deprivation syndrome" (Spitz \& Wolf, 1946), develops in an infant after loss of a caregiver and no provision of a substitute. Reactive depression differs from anaclitic depression in that loss of the caregiver does not invariably lead to anaclitic depression; poor parent-child relationships have the most impact on development of reactive depression (Abrahams \& Whitlock, 1969). Acute depression develops in response to some traumatic event, such as the loss of a loved one, and the prognosis for recovery is good (Cytryn \& McKnew, 1972). Chronic depression, in contrast, is more extreme and has no immediate precipitating events but is punctuated by repeated separations from the caregiver during early infancy. Finally, endogenous depression is thought to be genetic or biochemical in nature, and possibly related to learning disabilities in some children (Brumback \& Stanton, 1983). 


\section{TABLE 2}

Subtypes of Childhood and Adolescent Depression

\section{Subtype \\ Characteristics}

Anaclitic

Depression

Loss of caregiver with no provision for a substitute; period of misery followed by loss of interest in environment.

Reactive Trauma or loss frequently accompanied by feelings of Depression guilt for past failures; poor parent-child relationship is important factor.

Acute Onset occurs after some traumatic event; prognosis Depression for recovery is good if relationship with caregiver is healthy.

Chronic Repeated separations from caregiver beginning in Depression infancy; presence of depression in mother; no immediate precipitating event; periodic recurring emotionaldepriving experiences; suicidal ideation early in childhood.

Endogenous Genetically or biochemically determined; no identiDepression fiable stressors; believed to exist, to some degree, throughout life of child; may reach psychotic or suicidal proportions.

\section{IDENTIFICATION AND ASSESSMENT}

Upon examining prevalence figures of depression in children and adolescents, the importance for educators to identify this disorder becomes alarmingly apparent. The extent to which children and adolescents experience depressive symptomatology has been studied in school-based and clinical populations. Prevalence estimates usually are determined either through DSM-III diagnostic criteria or rating scales in which a score is translated into levels ranging from nondepressed to severely depressed (Reynolds, 1985). Because DSM-III focuses on clinical syndromes or symptom-clusters, prevalence estimates using this approach tend to be more conservative than those obtained for rating scales that provide only global indicators of symptom-severity. In fact, children obtaining rating scale scores in the severe range occasionally fail to meet DSM-III diagnostic criteria for depressive disorders (Kazdin, Colbus, \& Rodgers, 1986).

\section{Prevalence Estimates}

Using DSM-III criteria, about $2 \%$ of school-based children (Kashani et al., 1983; Kashani \& Simonds, 1979) and $10 \%$ to $20 \%$ of clinic-based children (Puig-Antich \& Gittelman, 1982) have been diagnosed as depressed. When depres- sion is identified using extreme scores on self report scales, between $2 \%$ and $17 \%$ of students attending general education school classes manifested moderate to severe levels of depressive symptomatology (Friedrich, Jacobs, \& Reams, 1982; Kaplan, Hong, \& Weinhold, 1984; Lefkowitz \& Tesiny, 1985; Reynolds, 1983; Smucker, Craighead, Craighead, \& Green, 1986; Teri, 1982a). Special education populations tend to have a much higher prevalence: Between $14 \%$ and $54 \%$ of learning disabled (LD) and seriously emotionally disturbed (SED) students manifested severe depressive symptomatology (Maag \& Behrens, 1989a; Mattison et al., 1986; Stevenson \& Romney, 1984).

A summary of selected prevalence studies is presented in Table 3. Only fairly recent studies employing large samples are included because they tend to be more accurate; however, considerable variability is evident, often depending on choice of diagnostic criteria and instrumentation.

Another reason prevalence estimates tend to be somewhat inchoate stems in part from the failure of researchers to consider variables such as gender and age. Gender differences in prevalence of depression usually do not surface until adolescence, when more females than males experience severe symptomatology (Angold, Weissman, John, Wickramaratne, Drusoff, 1991; Kashani et al., 1983; Lefkowitz \& Tesiny, 1985; Lobovits \& Handal, 1985; Mezzich \& Mezzich, 1979; Reinherz et al., 1989; Reynolds, 1985). Similar results have been obtained with LD and SED adolescents; females are three times more likely to report severe depressive symptomatology than their male counterparts (Maag \& Behrens, 1989b).

In regard to age, except for very young children (aged 1-6), who have low rates of depression (Kashani, Cantwell, Shekim, \& Reid, 1982; Kashani, Ray, \& Carlson, 1984), age differences in both handicapped and nonhandicapped populations tend to be mediated by gender (e.g., Fleming \& Offord, 1990; Maag \& Behrens, 1989a; Rutter, 1986). Adolescents in general, however, seem to experience higher rates of depression than children do (Forness, 1988; Kazdin, 1990).

\section{Educators' Perspectives on Depression}

Given the unsettling prevalence of depression in schoolbased populations, educators clearly should play a strategic role in early identification. Youngsters spend more time in school than in most other structured settings outside the home, and their most consistent and extensive contact is with educators (Grob, Klein, \& Eisen, 1983). Consequently, 


\section{TABLE 3}

\section{Selected Prevalence Findings in Childhood and Adolescent Depression}

\begin{tabular}{|c|c|c|}
\hline Study & Sample Type & $\begin{array}{c}\text { Percent } \\
\text { Depressed }\end{array}$ \\
\hline \multicolumn{3}{|l|}{$\begin{array}{l}\text { School-Based } \\
\text { General Education } \\
\text { Samples }\end{array}$} \\
\hline $\begin{array}{l}\text { Lefkowitz \& } \\
\text { Tesiny (1985) }\end{array}$ & $\begin{array}{l}3,020 \text { 3rd-, } 4 \text { th-, } \& \text { 5th- } \\
\text { grade children, mean age } 9.8\end{array}$ & $5.2 \%$ \\
\hline Reynolds (1983) & $\begin{array}{l}2,874 \text { adolescents, ages } \\
13-18\end{array}$ & $7 \%$ \\
\hline \multicolumn{3}{|l|}{$\begin{array}{l}\text { School-Based } \\
\text { Special Education } \\
\text { Samples }\end{array}$} \\
\hline $\begin{array}{l}\text { Maag \& } \\
\text { Behrens (1989a) }\end{array}$ & $\begin{array}{l}465 \text { LD and SED } \\
\text { adolescents ages } 12-18 \\
\text { attending resource programs }\end{array}$ & $21 \%$ \\
\hline $\begin{array}{l}\text { Mattison et al. } \\
\text { (1986) }\end{array}$ & $\begin{array}{l}109 \text { students ages } 6-18 \\
\text { referred for SED placement }\end{array}$ & $\begin{array}{l}18 \% \text { (ages } 6-12 \text { ) } \\
51 \% \text { (ages 13-18) }\end{array}$ \\
\hline $\begin{array}{l}\text { Stevenson \& } \\
\text { Romney (1984) }\end{array}$ & $\begin{array}{l}103 \text { LD students ages } 8-13 \\
\text { attending resource programs }\end{array}$ & $14 \%$ \\
\hline \multicolumn{3}{|l|}{$\begin{array}{l}\text { Clinic-Based } \\
\text { Samples }\end{array}$} \\
\hline $\begin{array}{l}\text { Cantwell \& } \\
\text { Baker (1982) }\end{array}$ & $\begin{array}{l}600 \text { children and adolescents } \\
\text { ages } 2-16 \text { presented to a } \\
\text { community clinic for speech } \\
\text { and language evaluation }\end{array}$ & $4 \%$ \\
\hline $\begin{array}{l}\text { Carlson \& } \\
\text { Cantwell (1980) }\end{array}$ & $\begin{array}{l}102 \text { children and adolescents } \\
\text { ages } 7-17 \text { presented for } \\
\text { psychiatric evaluation to an } \\
\text { outpatient department }\end{array}$ & $58 \%$ \\
\hline $\begin{array}{l}\text { Colbert, Newman, } \\
\text { Ney, \& Young } \\
(1982)\end{array}$ & $\begin{array}{l}282 \text { children and adolescents } \\
\text { ages } 6-14 \text { admitted to a child } \\
\text { and family practice unit }\end{array}$ & $54 \%$ \\
\hline
\end{tabular}

school personnel may be the first professionals to notice developing problems (Powers, 1979). To facilitate the identification process, school personnel must be knowledgeable of depression and sensitive to students who might exhibit it. Although school personnel possess some general knowledge of depression, they cleave to several misconceptions.

Maag, Rutherford, and Parks (1988) had a sample of regular education teachers, special education teachers, and school counselors complete a questionnaire assessing their ability to identify characteristics of depression. Their answers were coded into similar response categories and compared to information about depression drawn from empirical research. School counselors possessed the greatest knowledge of depression, whereas general and special educators identified only global characteristics. Of particular note, special educators tended to identify characteristics related to externalizing problems (e.g., disobedience, agression) more frequently than internalizing problems (e.g., sadness, loneliness, crying). Externalizing behaviors tend to correlate more highly to depression scores for males, and internalizing problems and negative view of self correlate more highly with depression scores for females (Smucker et al., 1986). More males than females typically receive special education services, so the belief in masked depression should not be resurrected.

In a similar study, Clarizio and Payette (1990) surveyed school psychologists. Although the school psychologists in the study possessed considerable knowledge of depression, their responses diverged relative to the literature in two important areas. First, a substantial number of school psychologists believed that childhood depression was substantively different from adult depression. They almost unanimously agreed that masked depression exists, even though this conceptualization has been discounted for several years (Kaslow \& Rehm, 1991). Second, projective techniques (e.g., TAT, sentence completion) were one of the most frequently named methods for assessing depression. This finding contradicts evidence that projective tests are not sensitive enough to identify specific psychiatric conditions in childhood, including depression (Gittelman, 1980).

More alarmingly, some evidence suggests that educators may respond more negatively to depressed students than to their nondepressed peers. Peterson, Wonderlich, Reaven, and Mullins (1987) had teachers rate their feelings in response to four films in which a child was portrayed as either depressed or nondepressed and as having experienced either high or low life stress. The children who were both depressed and stressed received the most negative reactions from educators; the children who were either depressed or stressed were viewed less negatively; and the children who were neither depressed nor stressed received the most positive reactions. Depression clearly influenced educators' responses in ways that could serve to maintain a child's depression. Educators who communicate less positive and more negative behavior to a depressed child may enhance feelings of low self-esteem, dysphoria, inadequacy, and helplessness.

Because the risk of suicide also is greatly heightened with depression (Myers et al., 1991), educators have a partic- 
ular need to be sensitive to this disorder. Guetzloe (1989) discusses issues of suicidality in school settings.

\section{Early Identification}

Early identification of depressed children and adolescents in school settings is desirable, but Reynolds (1986a) recognized several factors that make this goal problematic:

1. Prevalence figures may be somewhat misleading as depressive symptomatology tends to be overendorsed on the first administration of a self-report measure of depression. A second administration of the same measure shortly thereafter may not show depressive symptomatology. What happens is that a specific event or stressor may trigger a depressive episode, which may account for many cases of depression identified in prevalence surveys.

2. School personnel often have difficulty identifying specific symptom clusters associated with depression. To complicate matters, secondary teachers have limited contact with students.

3. Depressed students rarely refer themselves for help.

4. Some parents deny that their child may be suffering from a mood disorder.

On the basis of findings from prevalence studies of depression in children and adolescents and the lack of selfreferral, teacher referral, or parent referral, Reynolds (1986a) developed a three-stage screening program to identify depressed children and adolescents in school settings: (a) conducting large-group screening with self-report depression measures; (b) 3 to 6 weeks later retesting children who, on the basis of the large-group screening in Stage 1, meet cutoff score criteria for depression; and (c) conducting individual clinical interviews with children who manifest clinical levels of depression at both Stage 1 and Stage 2 evaluations.

Classroom teachers can conduct group assessment of students, utilizing a self-report depression measure appropriate for children or adolescents. Self-report is particularly important in assessing depression because primary symptoms such as sadness, feelings of worthlessness, and loss of interest in activities reflect subjective feelings and self-perceptions (Kazdin, 1990). Common self-report measures for children and adolescents are given in Table 4.

Reynolds (1986a) has suggested that teachers avoid telling students they are being tested for depression because this information may induce lower levels of mood awareness. Instead, students can be informed that the school is interested in how they are feeling about themselves. This information can be restated to students involved in a second screening. The second screening serves to weed out students who experienced a transient depressed mood during the initial screening or exaggerated their depressive symptomatology. During the last stage, individual clinical interviews are conducted with students who met depression criteria at both previous stages. Common interview schedules also are presented in Table 4. Obtaining measures other than self-reports is important as some students consistently overestimate or underestimate depressive symptomatology or misinterpret items or response format.

To screen initially for only a single disorder may be neither desirable nor efficient sometimes, especially given limited resources in some school psychology or consulting services budgets. As an alternative to screening only for depression, Walker and Severson (1990) have developed a multi-stage procedure to screen for both internalizing and externalizing disorders. In this process, teachers are asked to nominate and rank order pupils who demonstrate characteristics of these broad-band disorders in their classroom (Stage 1) but then also rate only the top three pupils in each category on brief measures of adaptive and maladaptive behavior as well as on critical events or symptoms (Stage 2). A school psychologist then conducts brief observations of classroom attention and playground social interaction on two different occasions (Stage 3 ) for any pupils who exceed critical cutoff scores in the first two stages. Although this procedure is not specific to depression, it may identify children with a potential diagnosis of this disorder, which then can be verified using the techniques described above.

\section{Depression-Related Characteristics}

Depression influences a wide range of behavioral, cognitive, and affective functioning (Maag \& Rutherford, 1987). Many depression-related characteristics vary as a function of developmental level (Kazdin, 1987). For example, infants have not acquired the ability to verbalize and have not experienced the world and therefore express depression through eating and sleeping disorders (Evans, Reinhart, \& Succop, 1980). Because preschoolers are motor-oriented, much of their mood is expressed through behavior such as night terrors, enuresis, and encopresis. Older school-age children may become more outwardly aggressive, anxious, and antisocial (Kazdin, French, \& Unis, 1983). Depression becomes more overt in adolescents as their better-developed conscience exacerbates feelings of guilt and low self-esteem (Teri, 1982b). 


\section{TABLE 4 \\ Commonly Used Measures for Childhood and Adolescent Depression}

\section{Measure \\ Self-Report (Child)}

Children's Depression Inventory

(Kovacs, 1985)

Reynolds Child Depression Scale (Reynolds, 1986b)

\section{Self-Report (Adolescent)}

Beck Depression Inventory (modified for adolescents)

(Chiles et al., 1980)

Reynolds Adolescent

Depression Scale

(Reynolds, 1986c)

\section{Clinical Interviews (Child)}

Bellevue Index of

Depression (Petti, 1978)

Children's Depression

Rating Scale

(Poznanski, Cook, \&

Carroll, 1979)

Schedule for Affective

Disorders for School-

Age Children (Chambers

et al., 1985)

\section{Clinical Interviews (Adolescent)}

Hamilton Depression

Rating Scale

(Hamilton, 1967)

Research Diagnostic

Criteria (Spitzer et al., 1978)

\section{Response Format}

27 items, each rated on a 0-2 point scale

30 items, each rated on a 1-5 point scale

33 items, each on a scale varying from 0 to 2,3 , or 4 points

30 items, each rated on a 4-point scale

40 items, each rated on a 4-point scale of severity and 3-point scale for duration

16 items scored after interview; symptoms rated on a 6-point scale for severity

Multiple items for mood disorders; depressive symptoms rated for degree of severity for scales varying in point values

17-item semi-structured interview with probes

11 depression subtypes (e.g., simple, recurrent, unipolar, agitated)

\section{Description}

Derived from Beck Depression Inventory (Beck, Ward, Mendelson, Mock, \& Erbaugh, 1961). Items reflect affective, cognitive, and behavioral symptoms.

Items selected to measure depression in school characteristics (e.g., suicide) are replaced by less severe behavior (e.g., hurting oneself).

Changes in language, not content of Beck Depression Inventory (Beck et al., 1961).

Items derived from symptoms included in major, minor, and unipolar depression.

Administered separately to child, parents, and others; helpful to combine scores from different sources.

Derived from Hamilton Depression Rating Scale (Hamilton, 1967) for adults. Administered also to parents and others to combine different sources.

Patterned after adult Schedule for Affective-Disorders (Endicott \& Spitzer, 1978) based on Research Diagnostic Criteria (Spitzer, Endicott, \& Robins, 1978). Parent and child are interviewed.

Measures severity of depression and probes for psychotic symptoms; translates well for use with adolescents.

Provides greater specificity than DSM classification; primarily used in research.

Note. For an in-depth review of the characteristics of individual assessment techniques, see Kazdin (1988).

A number of salient characteristics correlate with, if not contribute directly to, depression. Although the range of domains is quite large, several key characteristics occur quite frequently with depression. For example, low self-esteem is likely to be part of the symptom picture of depression. Hopelessness, or negative expectations toward the future, correlates with depression, suicidal ideation and behavior, and low self-esteem (DiGangi, Behrens, \& Maag, 1989; Kazdin, Rodgers, \& Colbus, 1986).

In addition to cognitive disturbances, social skill deficits often are associated with depression (Helsel \& Matson, 1984). Environmental events that induce stress can contribute to the development and maintenance of depression as well (Compas, 1987). These depression-related characteris- 
tics often reflect specific theoretical models of depression including social skill deficits, cognitive theory, learned helplessness theory, self-control deficits, and deficits in problem solving.

Descriptions of the relevant models are presented in Table 5. A number of measures focus on key areas related to depressive symptoms based on these theoretical models. Table 6 lists common measures that are used to assess areas central to current conceptual views of depression and convey areas reflecting specific theoretical models.

\section{Categorizing Problems Associated with Depression}

Based on current theoretical models, depression may result from social skill deficits, self-control deficits, learned helplessness attributions, or cognitive distortions or deficits. Interpersonal problem-solving skills contribute to both cognitive and behavioral conceptualizations (Braswell \& Kendall, 1988; Nezu, Nezu, \& Perri, 1989). Systematically approaching and evaluating problem situations represents a general orientation common to most intervention approaches. In addition, environmental factors, such as inappropriate or absent reinforcement contingencies, inhibit expression of healthy and positive functioning or promote depression and related characteristics.

Figure 1 illustrates a four-category conceptualization of problems associated with depression. According to this model, depression can be conceptualized as resulting from

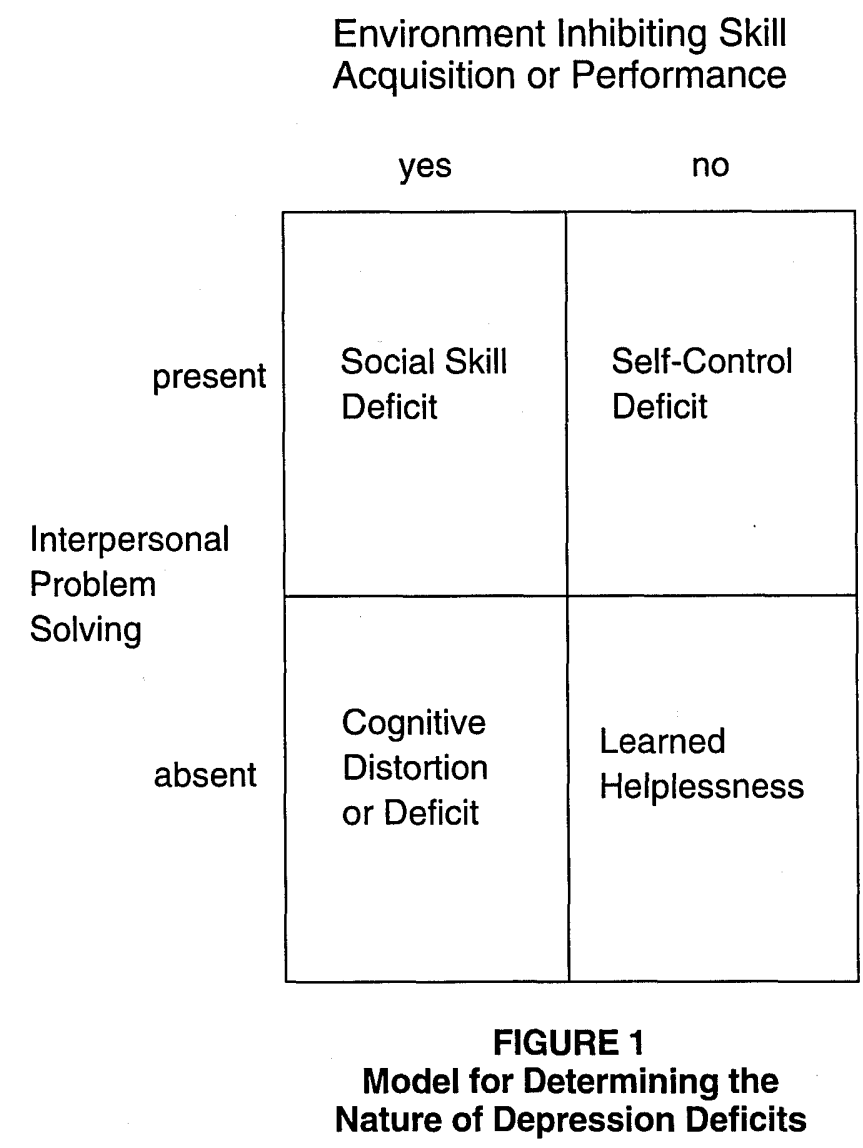

Acquisition or Performance

yes no

Nature of Depression Deficits

\section{TABLE 5}

\section{Theoretical Models Accounting for Depression}

\section{Model}

Social Skill

Deficits

Self-Control

Model

Learned

Helplessness

Cognitive

Triad of

Depression

Interpersonal Problem-

Solving Deficits

\section{Description}

Depression results from a lack of social skills necessary to obtain reinforcement from the environment (Lewinsohn, 1974) Low rates of response-contingent positive reinforcement results in reduced activity levels. Punishing and aversive consequences (unpleasant outcomes) may result from person-environment interactions and lead to symptoms of depression.

Maladaptive or deficient self-regulatory processes in coping with stress cause depression (Rehm, 1977). Self-regulatory processes include self-monitoring, self-evaluation, and self-reinforcement. Individuals with self-regulatory deficits focus on negative events, set overly stringent criteria for evaluating their performance, and administer little reinforcement to themselves.

Depression results from individuals' experiences and expectations that their responses do not influence events in their lives. Perfidious attributional style filters experiences in such a way as to produce deficits in affect, motivation, and self-esteem associated with depression (Abramson, Seligman, \& Teasdale, 1978).

Depressed individuals have a systematically negative bias in their thinking, which leads them to have a negative view of themselves, the world, and the future (Beck, 1967). Negative cognitions are considered to affect the individual's judgment about the world and interpersonal interactions, and to account for affective, motivational, and behavioral symptoms of depression.

Inability to generate alternative solutions to social problems, engage in means-end thinking, and make decisions exacerbate effects of negative events (Nezu, Nezu, \& Perri, 1989). Depression emerges in response to problems of daily living. 


\section{TABLE 6 \\ Common Measures for Assessing Depression-Related Characteristics \\ Description}

\section{Measure}

\section{Social Skills}

Matson Evaluation of Social Skills with Children (Matson, Rotatori, \& Helsel, 1983)

Walker-McConnell Scale of Social Competence and School Adjustment (Walker \& McConnell, 1988)

\section{Cognition}

Children's Attributional Style Questionnaire (Seligman \& Peterson, 1986)

Children's Negative Cognitive Error Questionnaire (Leitenberg, Yost, \& Carroll-Wilson, 1986)

\section{Problem Solving}

Problem Solving Measure for Conflict (Lochman \& Lampron, 1986)

Simulated Problem Situations (Gesten et al., 1982)

\section{Stressful Events}

Life Events Checklist (Johnson \& McCutcheon, 1980)

Life Events Record

(Coddington, 1972)

\section{Activities and Reinforcers}

Pleasure Scale for Children (Kazdin, 1989)

\section{Adolescent Activities}

(Carey, Kelley, Buss, \& Scott, 1986)

Children's Reinforcement Schedules (Cautela, Cautela, \& Esonis, 1983)

Adolescent Reinforcement Survey Schedule (Cautela, 1981)
Items pertain to social skills, assertiveness, jealousy, and impulsiveness as related to interpersonal interaction. Self-report and teacher-report forms rated on 5-point scale.

Teacher-rated scale consisting of 43 descriptions of peer-related interpersonal social skills and adaptive behavior required for success within classroom instructional settings.

Self-report measure consisting of 48 forced-choice items that permit assessment of three attributional dimensions considered important in a learned helplessness model of depression: internal-external characteristics, stable-unstable characteristics, and good-bad outcomes.

Self-report measure consisting of 24 items presenting hypothetical situations or events followed by a statement about the event that reflects cognitive errors (catastrophizing, overgeneralizing, personalizing, and selective abstraction). Children rate degree of similarity to their own thoughts. This measure is based on Beck's cognitive therapy of depression.

Six means-end stories with each stem describing a problematic situation and a conclusion in which the problem was no longer occurring. Children provide the middle. Scores are based on children's responses on three content areas: verbal assertion, direct action, and physical aggression. This measure is based on Shure and Spivack's (1972) means-ends problem-solving test.

Measures of children's natural problem-solving behavior when confronted with a simulated problem situation. Interactions between confederates and target children are observed. Scoring is based on number of alternative solutions generated, number of solution variants offered, number of irrelevant solutions generated, total number of solutions generated excluding irrelevant solutions, and effectiveness of solutions.

Self-report measure consisting of 46 items that list stressful events. Children indicate whether the event occurred in the past year, whether it was bad or good, and degree of impact on their lives.

Stressful events varying as a function of age whose occurrence is rated according to life change units. Parents complete the form for young children; older children complete the scale themselves.

Children report on a 3-point scale the extent to which 39 items would make them happy. The instrument measures degree of anhedonia.

Adolescents rate the frequency of occurrence of 100 activities for degree of pleasantness and unpleasantness experienced during the last 2 weeks. The measure is based on Lewinsohn's work.

Children identify events that can be used as reinforcers. Helpful as a method to assess pleasure children report in response to a variety of events.

Parallels Children's Reinforcement Schedules.

\footnotetext{
*Although many problem-solving measures have been reported in the literature, none are ideally suited for either research or practice (Butler \&
} Meichenbaum, 1981). 


\section{TABLE 7 \\ Treatment Strategies Following Theoretical Models of Depression}

Model
Social Skill Strategies

Self-Control Strategies

Helplessness Strategies

Cognitive Strategies

\begin{abstract}
Description
Main strategies include shaping procedures that use adult reinforcement, modeling or combined modeling and reinforcement procedures, and direct training procedures to make use of the child's cognitive and verbal skills. Specific training techniques include instructions, modeling, role playing, rehearsal, feedback, and selfmanagement techniques. Verbal-cognitive approaches emphasize teaching specific social skills and general problem-solving techniques.
\end{abstract}

Self-management strategies including self-monitoring, self-evaluation, self-reinforcement, and self-instruction would be appropriate for remediating self-control deficits. Intervention should take into account children's cognitive developmental capacities and require the practitioner to play an active role in effecting the desired change by utilizing action-oriented techniques and concrete tasks.

Strategies follow an attribution retraining conceptualization in which children are taught to take responsibility for their failure and to attribute success or failure to effort. Adaptive coping responses are substituted for attributions of helplessness.

Treatment focuses on determining the meaning of the child's nonverbal and verbal communication. Any distorted cognitions the child expresses must be challenged. Bestowing acceptance and affection are important, as is assigning tasks that ensure success experiences. Techniques are designed to help the child identify, reality-test, and modify distorted conceptualizations and dysfunctional attitudes and beliefs. social skill deficits, self-control deficits, cognitive distortions or deficits, and learned helplessness attributions. The presence of interpersonal problem-solving skills and environmental factors allows the categorization of depression for the basis of developing appropriate interventions. For example, poor social skills may result from erroneous problem solving or environmental factors. A child who is encouraged by his or her peers to participate in a game and is capable of performing the requisite behaviors but is unable to strategically select them probably indicates erroneous problem solving. Conversely, if the child lacks the behavioral requisites to participate in the game, social skill deficits may be targeted for intervention. Similarly, cognitive disturbances and misattributions may result from the child's inability to evaluate situations appropriately or perform the requisite behaviors.

\section{TREATMENT OF CHILDHOOD AND ADOLESCENT DEPRESSION}

The model depicting problems associated with depression presented in Figure 1 can be used to develop intervention programs for depressed youth. When developing a treatment program, the first consideration is whether depressive symptomatology represents a primary condition, (e.g., mood disorder) or is a byproduct of other behavior problems (Kaslow \& Rehm, 1991). For example, youngsters who are hyperactive, aggressive, school phobic, or socially incompetent may experience depressive symptomatology and related dysfunctional cognitions as a result of these problems (Maag, Behrens, \& DiGangi, 1991). If conventional treatments for these behavior problems are ineffective for ameliorating the primary problem and related depressive symptomatology, specific treatment strategies for depression should be employed.

Table 7 presents a summary of treatment approaches relative to theoretical models of depression. Intervention strategies generally reflect either behavioral or cognitivebehavioral orientations. Although techniques based on these models seem promising, only a few studies have investigated their efficacy with children and adolescents (see Maag, 1988a; Stark, 1990). In addition, Kazdin (1990) raises the issue of comorbidity (the individual meets criteria for more than one disorder). Several researchers have found that depression coexists with attention deficit disorders, conduct disorders, anxiety disorders, autism, and mental retardation (e.g, Anderson, Williams, McGhee, \& Silva, 1987; Bernstein, 1991; Bernstein \& Garfinkel, 1986; Bird et al., 1988; Fendrich, Weissman, \& Warner, 1991; Forness \& Kavale, in press; McClellan, Rupert, Reichler, \& Sylvester, 1990; Strauss, Last, Hersen, \& Kazdin, 1988).

Ironically, the phenomenon of comorbidity has led some researchers to suggest that it may be more meaningful 


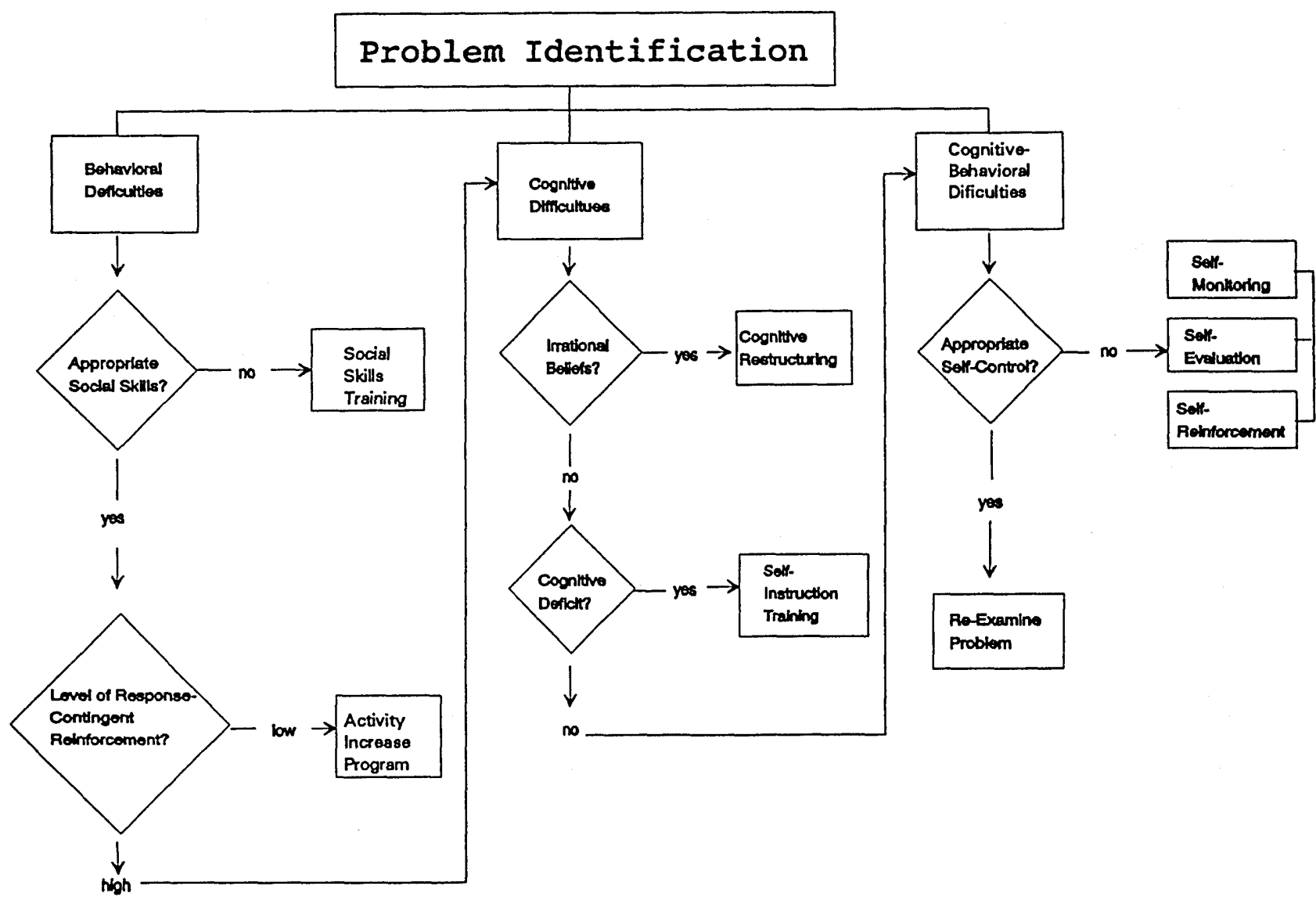

FIGURE 2

Flowchart for Determining Choice of Intervention Strategy

to conceptualize depression in terms of the broader classification of internalizing symptoms rather than the more specific symptomatology of depression, which is more difficult to distinguish (Wolfe et al., 1987). This finding is particularly germane to special educators, as problems of an internalizing nature tend to be frequent in children with learning problems (Thompson, 1986).

\section{Determining Choice of Strategies}

Given the range of deficits associated with depression, and their implications for treatment, it is important to determine which factor(s) seem most responsible for the development and maintenance of this disorder (Kaslow \& Rehm, 1991). Attempting to assess youngters' relative skills in each area is a tedious and exacting process. Nevertheless, to enhance treatment efficacy, intervention techniques should be matched to identified, specific problems (Maag, 1989).

In this regard, Kaslow and Rehm (1991) suggest sequencing potential intervention strategies and then making decisions on which ones to use in which order, depending on the results of assessment information. For example, if depression is secondary to a conduct or oppositional disorder, social skills training may be essential for the child to obtain an adequate level of response-contingent positive reinforcement in the environment. If the student's social skills are adequate, however, a more appropriate initial technique would be to modify the child's activity level.

Kaslow and Rehm (1991) also stressed the importance of eliciting overt behavior change prior to targeting cognitive factors, because overt behavior is easier to assess than selfreports of children's cognitions. In addition, obtaining an accurate sampling of the child's self-reported cognitions is 
easier once behavior has been modified. Figure 2 presents a modified version of the flowchart developed by Kaslow and Rehm (1991) for determining choice of intervention strategies. This figure is based on the need to accurately identify and define the problem using assessment measures previously described. Targets for intervention reflect three general areas: behavior, cognitive, and cognitive-behavioral. As with any aspect of depression in children and adolescents, care must be taken to modify intervention strategies based on the child's developmental level and level of cognitive, affective, and behavioral functioning (Cole \& Kaslow, 1988).

\section{Developing a Conceptual Model for Intervention}

Although the treatment literature for childhood and adolescent depression is relatively sparse compared to other areas such as conduct disorders or attention deficit disorders, several new studies have investigated a variety of training techniques. Table 8 provides a summary of recent treatment studies for childhood and adolescent depression. One of the difficulties encountered when treating depression is organizing and integrating the various techniques into a structured training format (Maag, 1988a). Attempting to implement all available techniques would be cumbersome and time-consuming. Yet, many depressed youths exhibit a variety of deficits, and employing a single intervention technique may not be sufficient.

A comprehensive training format would provide a structured system for employing various techniques systematically. One conceptual format is offered in the stress inoculation training (SIT) paradigm. SIT is a multi-component intervention format that combines elements of didactic teaching, Socratic discussion, cognitive restructuring, problem solving, relaxation training, behavioral and imaginal rehearsal, self-monitoring, self-instruction, self-reinforcement, and environmental manipulation (Meichenbaum, 1985). SIT should not be viewed as a loose compendium of unrelated methods, but, rather, a set of interconnected techniques that can be combined in a systematic way.

SIT is implemented in three phases: (a) conceptualization; (b) skills acquisition and rehearsal; and (c) application and follow-through. In Phase I, youngsters are educated about the causes, consequences, and alternative methods of handling depression. Phase II involves training youngsters in relevant skills for coping with depression. In Phase III, youngsters practice applying coping skills in vitro and in vivo during exposure to regulated doses of stressors that arouse but do not overwhelm their coping skills. SIT has been used to treat depression (Maag, 1988b) and for aggression and anger management (Feindler \& Fremouw, 1983; Maag, Parks, \& Rutherford, 1988) (see Maag, 1988a for an in-depth description of using stress inoculation training for treating depressed youths).

\section{Pharmacological Treatment}

Pharmacotherapy is an essential adjunct to behavioral and cognitive-behavioral interventions, particularly in cases with vegative symptomatology and family history of mood disorders (Cantwell \& Carlson, 1983; Gadow, 1986; Klein, Gittelman, Quitkin, \& Rifkin, 1980). Five classes of psychotropics are used in depression; these are depicted in Table 9 in terms of their uses, side effects, and related considerations (see Gadow, 1986; Greist \& Greist, 1979; Kazdin, 1990; and Petti, 1983 for reviews of pharmacological interventions). Imipramine seems to be the drug of choice for children and adolescents alike (Esman, 1981; Kashani, Shekim, \& Reid, 1984; Petti \& Law, 1982; Preskorn, Weller, \& Weller, 1982; Puig-Antich, 1982); but other drugs, such as lithium and tegretol, are widely used for adolescents who have variant forms of mood disorders (Campbell,-Schulman, \& Rapoport, 1978; Kishimoto, Ogura, Hazama, \& Inoue, 1983).

Although pharmacotherapy is prescribed by psychiatrists, school personnel should be aware of the types of drugs used and their potentially serious side effects. A classroom observation study documenting single-subject classroom effects of imipramine and lithium suggests important considerations for teachers (Forness, Akiyama, \& Campana, 1984). Educators need to become much more involved in evaluating effects of such medication on classroom-based measures of treatment outcome (Forness \& Kavale, 1988).

\section{Integrating Treatment}

Even as treatment of childhood and adolescent depression seems promising, factors external to the child should be considered. Because of parents' influence over their children, Kazdin (1990) suggests that family-based interventions should be incorporated into treatment programs. In this regard, teachers can play a pivotal role by cultivating positive relationships with parents. Positive parent-teacher relationships promote parental feedback to practitioners, enhance treatment outcomes, and extend positive effects of school programming into the home (Heward, Dardig, \& Rossett, 1979).

In addition, parents can become trainers of their children by structuring activities and managing behavioral con- 


\section{TABLE 8}

\section{Treatment Studies with Depressed Children and Adolescents}

\section{Treatment \\ Social Skills Training}

Study

Calpin \&

Cincirpini

(1978)

Calpin \&

Kornblith

(1977)

Fine,

Forth,

Gilbert, \&

Haley (1991)

Frame,

Matson,

Sonis,

Fialkov, \&

Kazdin

(1982)

Petti,

Bornstein,

Delamater, \&

Conners

(1980)

Matson et al. (1980)

Schloss

Schloss, \&

Harris (1984)

Butler,

Miezitis

Friedman, \&

Cole (1980)

Maag

(1988b)

Reynolds \&

Coats (1986)

Stark,

Kaslow, \&

Reynolds

(1987)
Sample

Two depressed inpatients (10-year-old girl, 11-yearold boy)

Four inpatient boys with aggressive behavior

Five groups of 30 adolescent outpatients

Borderline mentally retarded 10-year-old depressed male inpatient

Chronically depressed

10 1/2-year-old inpatient girl

Four depressed emotionally disturbed boys

Three depressed inpatient males

56 fifth- and sixth-grade students

56 adolescent inpatients

30 moderately depressed high school students

29 fourth-, fifth-, and sixth-grade students

\section{Findings}

Improvement for both children on specific social skills (e.g., eye contact)

Improvement of all boys on specific social skills (e.g., requests for new behaviors)

Improvement to "nonclinical" levels on depression scales, but to a lesser degree than subjects receiving group therapy

Improvement on all target behaviors (e.g., inappropriate body position, lack of eye contact, poor speech quality)

Improvement on all target behaviors (e.g., eye contact, smiles, duration of speech)

Increased positive social responses on role-play scenarios for target behaviors (e.g., giving compliments)

Improvement on five target behaviors (e.g., greets adult, maintains conversation, says goodbye)

Decreases in depression for role-play and cognitive restructuring conditions; most improvement for role-play

Decreases in depression and negative self-statement for subjects receiving stress inoculation training

Decreases in depression and anxiety for subjects receiving either cognitive restructuring or relaxation training

Decreases in depression for subjects receiving either selfcontrol or problem-solving training 
TABLE 9

\section{Common Psychopharmacologic Medication Used with Depressed Children or Adolescents}

\section{Type \\ (Trade name)}

Tricyclics:

Imipramine

(Tofranil)
Indication

Unipolar in

children

Unipolar in adolescents

Unipolar in adolescents (little research with children)

$\begin{array}{ll}\text { Lithium } & \text { Bipolar in } \\ \text { Carbonate } & \text { adolescents } \\ \text { (Lithonate) } & \text { and occasion- } \\ & \text { ally in multiple } \\ & \text { episodes of } \\ & \text { unipolar }\end{array}$

Monoamine
Oxidase
Inhibitors
(Nardil)

Carbamazepine (Tegretol)

Fluoxetine Hydrochloride (Prozac) depression in adolescents

Bipolar in adolescents, especially rapid-cycling

\section{Unipolar} depression in adolescents

Dosage* $^{\text {10-175 mg }}$
$75-225 \mathrm{mg}$

Therapeutic Effects

Improvement in vegetative symptoms at first, followed by improvement in mood some 3 or 4 weeks later

$450-1800 \mathrm{mg}$

Improvement in symptoms in 4-10 days, with most of effect within first 2 weeks; "smooths" rather than eliminates symptoms, but early treatment may suppress recurrences

$30-60 \mathrm{mg}$

$$
20-80 \mathrm{mg}
$$

Side Effects

Dry mouth, drowsiness (especially Elavil), blurred vision, constipation, cardiac arrythmias (EKG monitoring is essential and overdose in suicidal patients becomes a concern)

\section{Other \\ Considerations}

After offset of 1 month, discontinue gradually over 3 or more months (withdrawal symptoms mimic depression). Has been used to treat separation anxiety, hyperactivity, enuresis.
Nausea, drowsiness, thirst, frequent urination, hand tremor, possible cardiac or kidney problems
Small dose added to tricyclic medication during withdrawal as long-term prophylaxis against recurrence. Has been used to treat aggression.

\section{Gradual} improvement over

Relatively more rapid onset of improvement

Nausea, dizziness, fainting, sleep disturbance and possible fatal reactions upon ingestion of certain cheese or yeast products

Nausea, drowsiness, weight loss, ataxia in instances, and possible toxic reactions with lithium

Anxiety,
nervousness,
insomnia, weight
loss, hypomania
or mania, and
seizures

Anxiety,

improvement over 5-6 weeks (long-term effects have not been systematically studied)
Used primarily in intractable conditions refractory to other drugs.

\begin{abstract}
Primarily a seizure medication but has been used in lithiumresistant depression.
\end{abstract}

Prozac has not been systematically studied for its potential for abuse, tolerance, or physical dependence

*These are doses in what have generally been considered as optimum levels and, in most cases, are determined on a mg/kg ratio based on body weight. Dosage levels vary widely, so these ranges should be considered with caution. 
tingencies that promote participation in activities and social interaction (Kazdin, 1990). Parents have effectively implemented reinforcement and punishment techniques and taught prosocial behaviors to their children with externalizing behaviors (e.g., Kazdin, 1985; Patterson, 1982). Parent programs have resulted in decreases in maternal depression and increases in family cohesion (e.g., Eyberg \& Robinson, 1982; Forehand, Wells, \& Griest, 1980; Karoly \& Rosenthal, 1977; Patterson \& Fleischman, 1979).

School-based intervention adds several other dimensions as well. Many special educators already conduct social skills training and utilize other cognitive-behavioral techniques for working with aggressive and socially incompetent youngsters (Maag, 1990). Treating depression represents a natural extension of these responsibilities. Furthermore, peers can be recruited for the intervention process as they represent a resource for promoting entrapment (McConnell, 1987) of behaviors that may combat depression. Special educators, therefore, can play a vital role in the early identification, assessment, and treatment of depression.

\section{SUMMARY AND CONCLUSION}

Depression represents one of the most significant mental health problems facing children and adolescents. An emerging body of research addresses the nature and characteristics of this disorder in school-aged populations, but educators just recently have begun to address this problem. Part of the difficulty has been educators' lack of knowledge of this disorder and its impact on youngsters' functioning.

Early identification is considered essential, and schools should play an important role in this process. Assessment should focus not only on depressive symptomatology but also on related characteristics, such as social skills. Perhaps most important in treating depression from a school standpoint is that many special educators currently employ many of the intervention strategies that are effective for ameliorating depression for a variety of other conditions such as conduct and attentional disorders. Treatment can be enhanced by sequencing intervention techniques systematically and employing a structured training format.

No one intervention approach will be optimally effective with each youngster. Youngsters who have similar depressive symptomatology may vary greatly with respect to etiological factors, related characteristics, and environmental circumstances. For this reason, depression must be viewed from a holistic framework. This model should guide the development and implementation of treatment decisions. In sum, decisions regarding depression should be made on the basis of empirically based knowledge and the youngster's specific characteristics.

\section{REFERENCES}

Abrahams, M. J., \& Whitlock, F. A. (1969). Childhood experience and depression. British Journal of Psychiatry, 115, 883-888.

Abramson, L. Y., Seligman, M. E. P., \& Teasdale, J. D. (1978). Learned helplessness in humans: Critique and reformulation. Journal of Abnormal Psychology, 87, 49-74.

American Psychiatric Association. (1987). Diagnostic and statistical manual of mental disorders-Revised (3rd ed.). Washington, DC: American Psychiatric Association.

Anderson, J. C., Williams, S., McGhee, R., \& Silva, P. A. (1987). The prevalence of DSM-III disorders in pre-adolescent children: Prevalence in a large sample from the general population. Archives of General Psychiatry, 44, 69-76.

Angold, A., Weissman, M. M., John, K., Wickramaratne, P., \& Drusoff, B. (1991). The effects of age and sex on depression ratings in children and adolescents. Journal of the American Academy of Child and Adolescent Psychiatry, 30, 67-74.

Beck, A. T. (1967). Cognitive therapy and the emotional disorders. New York: International Universities Press.

Beck, A. T., Ward, C. H., Mendelson, M., Mock, J., \& Erbaugh, J. (1961). An inventory for measuring depression. Archives of General Psychiatry, 4, 53-63.

Bernstein, G. A. (1991). Comorbidity and severity of anxiety and depressive disorders in a clinic sample. Journal of the American Academy of Child and Adolescent Psychiatry, 30, 43-50.

Bernstein, G. A., \& Garfinkel, D. B. (1986). School phobia: The overlap of affective and anxiety disorders. Journal of the American Academy of Child Psychiatry, 25, 235-241.

Bird, H. R., Canino, G., Rubio-Stipec, M., Gould, M. S., Ribera, J., Sesman, M., Woodbury, M., Huertas-Goldman, S., Pagan, A., Sanchez-Lacay, A., \& Moscoso, M. (1988). Estimates of the prevalence of childhood maladustment in a community survey of Puerto Rico: The use of combined measures. Archives of General Psychiatry, 45, 1120-1126.

Braswell, L., \& Kendall, P. C. (1988). Cognitive-behavioral methods with children. In K. S. Dobson (Ed.), Handbook of cognitive-behavioral therapies (pp. 167-213). New York: Guilford.

Brumback, R. A., \& Stanton, R. D. (1983). Learning disability and childhood depression. American Journal of Orthopsychiatry, 53, 269-281.

Butler, L., \& Meichenbaum, D. (1981). The assessment of interpersonal problem-solving skills. In P. C. Kendall \& S. D. Hollon (Eds.), Assessment strategies for cognitive-behavioral interventions (pp. 197-225). New York: Academic Press.

Butler, L., Miezitis, S., Friedman, R., \& Cole, E. (1980). The effect of two school-based intervention programs on depressive symptoms in preadolescents. American Education Research Journal, 17, 111-119.

Calpin, J. P., \& Cincirpini, P. M. (1978, May). A multiple baseline analysis of social skills training in children. Paper presented at Midwestern Association for Behavior Analysis, Chicago.

Calpin, J. P., \& Kornblith, S. J. (1977). Training of aggressive children in conflict resolution skills. Paper presented at meeting of Association for the Advancement of Behavior Therapy, Chicago. 
Campbell, M., Schulman, D., \& Rapoport, J. L. (1978). The current status of lithium therapy in child and adolescent psychiatry. Journal of Child Psychiatry, 17, 717-720.

Cantwell, D. P., \& Baker, L. (1982). Depression in children with speech, language, and learning disorders. Journal of Children in Contemporary Society, 15, 51-59.

Cantwell, D. P., \& Carlson, G. A. (Eds.). (1983). Affective disorders in childhood and adolescence: An update. New York: Spectrum.

Carey, M. P., Kelley, M. L., Buss, R. R., \& Scott, W. O. N. (1986). Relationship of activity of depression in adolescents: Development of the Adolescent Activities Checklist. Journal of Consulting \& Clinical Psychology, 54, 320-322.

Carlson, G. A., \& Cantwell, D. P. (1980). Unmasking depression in children and adolescents. American Journal of Psychiatry, 137, 445-449.

Carlson, G. A., \& Garber, J. (1986). Developmental issues in the classification of depression in children. In M. Rutter, C. E. Izard, \& P. B. Read (Eds.), Depression in young people: Developmental and clinical perspectives (pp. 399-435). New York: Guilford.

Cautela, J. R. (1981). Behavior analysis forms for clinical intervention (Vol. 2). Champaign, IL: Research Press.

Cautela, J. R., Cautela, J., \& Esonis, S. (1983). Forms for behavior analysis with children. Champaign, IL: Research Press.

Chambers, W. J., Puig-Antich, J., Hirsch, M., Paez, P., Ambrosini, P. J., Tabrizi, M. A., \& Davies, M. (1985). The assessment of affective disorders in children and adolescents by semistructured interview: Testretest reliability. Archives of General Psychiatry, 43, 696-702.

Chiles, J. A., Miller, M. L., \& Cox, G. B. (1980). Depression in an adolescent delinquent population. Archives of General Psychiatry, 37, 1179-1184.

Cicchetti, D., \& Schneider-Rosen, K. (1986). An organizational approach to childhood depression. In M. Rutter, C. E. Izard, \& P. B. Read (Eds.), Depression in young people: Developmental and clinical perspectives (pp. 71-134). New York: Guilford.

Clarizio, H. F., \& Payette, K. (1990). A survey of school psychologists' perspectives and practices with childhood depression. Psychology in the Schools, 27, 57-63.

Coddington, R. D. (1972). The significance of life events as etiological factors in the diseases of children: A study of normal population. Journal of Psychosomatic Research, 16, 205-213.

Colbert, P., Newman, B., Ney, P., \& Young, J. (1982). Learning disabilities as a symptom of depression in children. Journal of Learning Disabilities, 15, 333-336.

Cole, P. M., \& Kaslow, N. J. (1988). Interactional and cognitive strategies for affect regulation: A developmental perspective on childhood depression. In L. B. Alloy (Ed.), Cognitive processes in depression (pp. 310-343). New York: Guilford.

Compas, B. E. (1987). Stress and life events during childhood and adolescence. Clinical Psychology Review, 7, 275-302.

Cytryn, L., \& McKnew, D. H. (1972). Proposed classification of childhood depression. American Journal of Psychiatry, 129, 149-155.

Cytryn, L., \& McKnew, D. H. (1974). Factors influencing the changing clinical expression of the depressive process in children. American Journal of Psychiatry, 131, 879-881.

DiGangi, S. A., Behrens, J. T., \& Maag, J. W. (1989). Dimensions of depression: Factors associated with hopelessness and suicidal intent among special populations. In R. B. Rutherford, Jr., \& S. A. DiGangi (Eds.), Severe behavior disorders of children and youth (Vol. 12, pp. 47-53). Reston, VA: Council for Children with Behavioral Disorders.
Dolgan, J. I. (1990). Depression in children. Pediatric Annals, 19, 45-50.

Endicott, J., \& Spitzer, R. L. (1978). A diagnostic interview: The Schedule for Affective Disorders and Schizophrenia. Archives of General Psychiatry, 35, 837-844.

Epstein, M. H., \& Cullinan, D. (1984). Research issues in behavior disorders: A national survey. Behavioral Disorders, 10, 56-59.

Esman, A. H. (1981). Appropriate use of psychotropics in adolescents. Hospital, 12, 49-60.

Evans, S., Reinhart, J., \& Succop, R. (1980). Failure to thrive: A study of 45 children and their families. In S. Harrison \& J. McDermott (Eds.), New directions in childhood psychopathology. New York: International Universities Press.

Eyberg, S. M., \& Robinson, E. A. (1982). Parent-child interaction training: Effects of family functioning. Journal of Clinical Child Psychology, $11,130-137$.

Feindler, E. L., \& Fremouw, W. (1983). Stress inoculation training for adolescent anger problems. In D. Meichenbaum \& M. Jaremko (Eds.), Stress reduction and prevention (pp. 451-485). New York: Plenum.

Fendrich, M., Weissman, M. M., \& Warner, V. (1991). Longitudinal assessment of major depression and anxiety disorders in children. Journal of the American Academy of Child and Adolescent Psychiatry, 30, 38-42.

Fine, S., Forth, A., Gilbert, M., \& Haley, G. (1991). Group therapy for adolescent depressive disorder: A comparison of social skills and therapeutic support. Journal of the American Academy of Child and Adolescent Psychiatry, 30, 79-85.

Fleming, J. E., \& Offord, D. R. (1990). Epidemiology of childhood depressive disorders: A critical review. Journal of the American Academy of Child and Adolescent Psychiatry, 29, 571-580.

Forehand, R., Wells, K. C., \& Griest, D. L. (1980). An examination of the social validity of a parent training program. Behavior Therapy, 11, 488-502.

Forness, S. R. (1988). School characteristics of children and adolescents with depression. In R. B. Rutherford, Jr., C. M. Nelson, \& S. R. Forness (Eds.), Bases of severe behavioral disorders in children and youth (pp. 177-203). San Diego: College-Hill Press.

Forness, S. R., Akiyama, K., \& Campana, K. (1984, November). Problems in antidepressant medication and classroom performance. Paper presented at Annual Conference on Severe Behavioral Disorders of Children and Youth, Tempe, AZ.

Forness, S. R., \& Kavale, K. A. (1988). Psychopharmacologic treatment: A note on classroom effects. Journal of Learning Disabilities, 21, 144-147.

Forness, S. R., \& Kavale, K. A. (in press). School identification and response to conduct disorders. In A. Duchnowski \& R. Friedman (Eds.), Conduct disorders: Research, practice, and issues. Tampa: Florida Mental Health Research Institute.

Frame, C., Matson, J. L., Sonis, W. A., Fialkov, M. J., \& Kazdin, A. E. (1982). Behavioral treatment of depression in a prepubertal child. Journal of Behavior Therapy \& Experimental Psychiatry, 13, 239-243.

Friedrich, W., Jacobs, J., \& Reams, R. (1982). Depression and suicidal ideation in early adolescents. Journal of Youth and Adolescence, 11, 403-407.

Gadow, K. D. (1986). Children on medication: Volume 2. Epilepsy, emotional disturbance, and adolescent disorders. San Diego: College-Hill Press.

Gesten, E. L., Rains, M. H., Rapkin, B. D., Weissberg, R. P., Flores de Apodaca, R., Cowen, E. L., \& Bowen, R. (1982). Training children in 
social problem-solving competencies: A first and second look. American Journal of Community Psychology, 10, 95-115.

Gittelman, R. (1980). The role of psychological tests for differential diagnosis in child psychiatry. Journal of the American Academy of Child Psychiatry, 19, 413-438.

Greist, J. H., \& Greist, T. H. (1979). Antidepressant treatment: The essentials. Baltimore: Williams and Wilkins.

Grob, M. C., Klein, A. A., \& Eisen, S. V. (1983). The role of the high school professional in identifying and managing adolescent suicidal behavior. Journal of Youth \& Adolescence, 12, 163-173.

Guetzloe, E. C. (1989). Youth suicide: What the educator should know. Reston, VA: Council for Exceptional Children.

Hamilton, M. (1967). Development of a rating scale for primary depressive illness. British Journal of Social \& Clinical Psychology, 6, 278-296.

Helsel, W. J., \& Matson, J. L. (1984). Assessment of depression in children: The internal structure of the Child Depression Inventory (CDI). Behaviour Research and Therapy, 22, 289-298.

Heward, W. L., Dardig, J. C., \& Rossett, A. (1979). Working with parents of handicapped children. Columbus, $\mathrm{OH}$ : Charles E. Merrill.

Johnson, J. H., \& McCutcheon, S. M. (1980). Assessing life stress in older children and adolescents: Preliminary findings with the Life Events Checklist. In I. G. Sarason \& C. D. Spielberger (Eds.), Stress and anxiety (Vol. 7, pp. 111-125). Washington, DC: Hemisphere.

Kaplan, S. L., Hong, G. K., \& Weinhold, C. (1984). Epidemiology of depressive symptomatology in adolescents. Journal of the American Academy of Child Psychiatry, 23, 91-98.

Karoly, P., \& Rosenthal, M. (1977). Training parents in behavior modification: Effects on perceptions of family interaction and deviant child behavior. Behavior Therapy, 8, 406-410.

Kashani, J. H., Barbero, G. J., \& Bolander, F. D. (1981). Depression in hospitalized pediatric patients. Journal of the American Academy of Child Psychiatry, 20, 123-134.

Kashani, J. H., Cantwell, D. P., Shekim, W. O., \& Reid, J. C. (1982). Major depressive disorder in children admitted to an inpatient community mental health center. American Journal of Psychiatry, 139, 671-672.

Kashani, J. H., McGee, R. O., Clarkson, S. E., Anderson, J. C., Walton, L. A., Williams, S., Silva, P. A., Robins, A. J., Cytryn, L., \& McKnew, D. H. (1983). Depression in a sample of 9-year old children. Archives of General Psychiatry, 40, 1217-1223.

Kashani, J. H., Ray, J. S., \& Carlson, G. A. (1984). Depression and depression-like states in preschool-age children in a child development unit. American Journal of Psychiatry, 141, 1397-1402.

Kashani, J. H., Shekim, W. O., \& Reid, J. C. (1984). Amitriptyline in children with major depressive disorder: A double-blind crossover pilot study. Journal of Child Psychiatry, 23, 248-251.

Kashani, J. H., \& Simonds, J. F. (1979). The incidence of depression in children. American Journal of Psychiatry, 136, 1203-1205.

Kaslow, N. J., \& Rehm, L. P. (1991). Childhood depression. In R. J. Morris \& T. R. Kratochwill (Eds.), The practice of child therapy (2nd ed., pp. 27-51). New York: Pergamon.

Kazdin, A. E. (1985). Treatment of antisocial behavior in children and adolescents. Homewood, IL: Dorsey.

Kazdin, A. E. (1987). Assessment of childhood depression: Current issues and strategies. Behavioral Assessment, 9, 291-319.

Kazdin, A. E. (1988). Childhood depression. In E. J. Mash \& L. G. Terdal (Eds.), Behavioral assessment of childhood disorders (2nd ed., pp. 157-195). New York: Guilford.

Kazdin, A. E. (1989). Evaluation of the pleasure scale in the assessment of anhedonia in children. Journal of the American Academy of Child and Adolescent Psychiatry, 28, 364-372.

Kazdin, A. E. (1990). Childhood depression. Journal of Child Psychology \& Psychiatry, 31, 121-160.

Kazdin, A. E., Colbus, D., \& Rodgers, A. (1986). Assessment of depressive disorder among psychiatrically disturbed children. Journal of Abnormal Child Psychology, 14, 499-515.

Kazdin, A. E., French, A., \& Unis, A. (1983). Child, mother, and father evaluations of depression in psychiatric inpatient children. Journal of Abnormal Child Psychology, 11, 167-180.

Kazdin, A. E., Rodgers, A., \& Colbus, D. (1986). The Hopelessness Scale for Children: Psychometric characteristics and concurrent validity. Journal of Consulting \& Clinical Psychology, 54, 241-245.

Kendall, P. C., Hollon, S. D., Beck, A. T., Hammen, C. L., \& Ingram, R. E. (1987). Issues and recommendations regarding use of the Beck Depression Inventory. Cognitive Therapy \& Research, 11, 289-299.

Kishimoto, A., Ogura, C., Hazama, H., \& Inoue, H. (1983). Long-term prophylactic effects of carbamazopine in affective disorder. British Journal of Psychiatry, 143, 327-331.

Klein, D. F., Gittelman, R., Quitkin, F., \& Rifkin, A. (1980). Diagnosis and drug treatment of psychiatric disorders in adults and children (2nd ed.). Baltimore: Williams and Wilkins.

Kovacs, M. (1985). The Children's Depression Inventory. Psychopharmacology Bulletin, 21, 995-998.

Kovacs, M. (1989). Affective disorder in children and adolescents. American Psychologist, 44, 209-215.

Lefkowitz, M. M., \& Burton, N. (1978). Childhood depression: A critique of the concept. Psychological Bulletin, 85, 716-726.

Lefkowitz, M. M., \& Tesiny, E. P. (1985). Depression in children: Prevalence and correlates. Journal of Consulting \& Clinical Psychology, 53, 647-656.

Leitenberg, H., Yost, L. W., \& Carroll-Wilson, M. (1986). Negative cognitive errors in children: Questionnaire development, normative data, and comparisons between children with and without self-reported symptoms of depression, low self-esteem, and evaluation anxiety. Journal of Consulting \& Clinical Psychology, 54, 528-536.

Lewinsohn, P. N. (1974). Clinical and theoretical aspects of depression. In K. S. Calhoun, H. E. Adams, \& K. M. Mitchell (Eds.), Innovative treatment methods of psychopathology (pp. 63-120). New York: Wiley.

Lobovits, D. A., \& Handal, P. J. (1985). Childhood depression: Prevalence using DSM-III criteria and validity of parent and child depression scales. Journal of Pediatric Psychology, 10, 45-54.

Lochman, J. W., \& Lampron, L. B. (1986). Situational Social problem-solving skills and self-esteem of aggressive and nonaggressive boys. Journal of Abnormal Child Psychology, 13, 527-538.

Maag, J. W. (1988a). Treatment of childhood and adolescent depression: Review and recommendations. In R. B. Rutherford, Jr., \& J. W. Maag (Eds.), Severe behavior disorders of children and youth (Vol. 11, pp. 49-63). Reston, VA: Council for Children with Behavioral Disorders.

Maag, J. W. (1988b). Treatment of adolescent depression with stress inoculation training. Unpublished doctoral dissertation, Arizona State University, Tempe.

Maag, J. W. (1989). Assessment in social skills training: Methodological and conceptual issues for research and practice. Remedial \& Special Education, 10(4), 6-17.

Maag, J. W. (1990). Social skills training in schools. Special Services in the Schools, 6, 1-19. 
Maag, J. W., \& Behrens, J. T. (1989a). Depression and cognitive self-statements of learning disabled and seriously emotionally disturbed adolescents. Journal of Special Education, 23, 17-27.

Maag, J. W., \& Behrens, J. T. (1989b). Epidemiologic data on seriously emotionally disturbed and learning disabled adolescents reporting extreme depressive symptomatology. Behavioral Disorders, 15, 21-27.

Maag, J. W., Behrens, S. T., \& DiGangi, S. A. (1991). Dysfunctional cognitions associated with adolescent depression: Findings across special populations. Manuscript submitted for publication.

Maag, J. W., Parks, B. T., \& Rutherford, R. B., Jr. (1988). Generalization and behavior covariation of aggression in children receiving stress inoculation therapy. Child \& Family Behavior Therapy, 10, 29-47.

Maag, J. W., \& Rutherford, R. B., Jr. (1987). Behavioral and learning characteristics of childhood and adolescent depression: Implications for special educators. In S. Braaten, R. B. Rutherford, Jr., \& J. W. Maag (Eds.), Programming for adolescents with behavioral disorders (Vol. 3, pp. 55-70). Reston, VA: Council for Children with Behavioral Disorders.

Maag, J. W., \& Rutherford, R. B., Jr. (1988). Review and synthesis of three components for identifying depressed students. In R. B. Rutherford, Jr., C. M. Nelson, \& S. R. Forness (Eds.), Bases of severe behavioral disorders in children and youth (pp. 205-230). San Diego, CA: College-Hill Press.

Maag, J. W., Rutherford, R. B., Jr., \& Parks, B. T. (1988). Secondary school professionals; ability to identify depression in adolescents. Adolescence, $23,73-82$.

Malmquist, C. P. (1977). Childhood depression: A clinical and behavioral perspective. In J. G. Schulterbrandt \& A. Raskin (Eds.), Depression in children: Diagnosis, treatment and conceptual models (pp. 33-59). New York: Raven.

Matson, J. L., Esveldt-Dawson, K., Andraski, F., Ollendick, T. H., Petti, T. A., \& Hersen, M. (1980). Observation and generalization effects of social skills training with emotionally disturbed children. Behavior Therapy, 11, 522-531.

Matson, J. L., Rotatori, A. F., \& Helsel, W. J. (1983). Development of a rating scale to measure social skills in children: The Matson Evaluation of Social Skills with Youngsters (MESSY). Behaviour Research and Therapy, 21, 335-340.

Mattison, R. E., Humphrey, F. J., Kales, S. N., Handford, H. A., Finkenbinder, R. L., \& Hernit, R. C. (1986). Psychiatric background and diagnoses of children evaluated for special class placement. Journal of the American Academy of Child Psychiatry, 25, 514-520.

McClellan, J. M., Rupert, M. P. M., Reichler, R. J., \& Sylvester, C. E. (1990). Attention deficit disorder in children at risk for anxiety and depression. Journal of the American Academy of Child and Adolescent Psychiatry, 29, 534-539.

McConnell, S. R. (1987). Entrapment effects and the generalization and maintenance of social skills training for elementary school students with behavioral disorders. Behavioral Disorders, 12, 252-263.

Meichenbaum, D. (1985). Stress inoculation training. New York: Pergamon.

Mezzich, A. C., \& Mezzich, J. E. (1979). Symptomatology of depression in adolescence. Journal of Personality Assessment, 43, 267-275.

Mitchell, J., McCauley, E., Burke, P. M., \& Moss, S. J. (1988). Phenomenology of depression in children and adolescents. Journal of the American Academy of Child and Adolescent Psychiatry, 27, 12-20.

Myers, K., McCauley, E., Calderon, R., Mitchell, J., Burke, P., \& Schloredt, K. (1991). Risks for suicidality in major depressive disorders. Journal of the American Academy of Child and Adolescent Psychiatry, 30, 86-94.

Nezu, A. M., Nezu, C. M., \& Perri, M. G. (1989). Problem-solving therapy for depression: Theory, research and clinical guidelines. New York: Wiley.

Patterson, G. R. (1982). Coercive family process. Eugene, OR: Castalia.

Patterson, G. R., \& Fleischman, M. J. (1979). Maintenance of treatment effects: Some considerations concerning family systems and follow-up data. Behavior Therapy, 10, 168-185.

Peterson, L., Wonderlich, S. A., Reaven, N. M., \& Mullins, L. L. (1987). Adult educators' response to depression and stress in children. Journal of Social \& Clinical Psychology, 5, 51-58.

Petti, T. A. (1978). Depression in hospitalized child psychiatry patients: Approaches to measuring depression. Journal of the American Academy of Child Psychiatry, 22, 11-21.

Petti, T. A. (1983). Imipramine in the treatment of depressed children. In D. P. Cantwell \& G. A. Carlson (Eds.), Affective disorders in childhood and adolescence: An update (pp. 375-415). New York: Spectrum.

Petti, T. A., Bornstein, M., Delamater, A., \& Conners, C. K. (1980). Evaluation and multimodal treatment of a depressed prepubertal girl. Journal of the American Academy of Child Psychiatry, 19, 690-702.

Petti, T. A., \& Law, W. (1982). Imipramine treatment of depressed children: A double-blind pilot study. Journal of Clinical Psychopharmacology, 2, 107-110.

Powers, D. (1979). The teacher and the adolescent suicide threat. Journal of School Health, 49, 561-563.

Poznanski, E. O., Cook, S. C., \& Carroll, B. J. (1979). A depression rating scale for children. Pediatrics, 64, 442-450.

Preskorn, S. H., Weller, E. B., \& Weller, R. A. (1982). Depression in children: Relationship between plasma imipramine levels and response. Journal of Clinical Psychiatry, 43, 450-453.

Puig-Antich, J. (1982). Major depression and conduct disorder in prepuberty. Journal of Child Psychiatry, 21, 118-128.

Puig-Antich, J., \& Gittelman, R. (1982). Depression in childhood and adolescence. In E. S. Paykel (Ed.), Handbook of affective disorders (pp. 379-392). New York: Guilford.

Rehm, L. P. (1977). A self-control model of depression. Behavior Therapy, $8,787-804$.

Reinherz, H. Z., Stewart-Berghauer, G., Pakiz, B., Frost, A. K., Moeykens, B. A., \& Holmes, W. M. (1989). The relationship of early risk and current mediators to depressive symptomatology in adolescence. Journal of the American Academy of Child and Adolescent Psychiatry, 28, 942-947.

Reynolds, W. M. (1983, March). Depression in adolescents: Measurement, epidemiology, and correlates. Paper presented at annual meeting of National Association of School Psychologists, Detroit.

Reynolds, W. M. (1984). Depression in children and adolescents: Phenomenology, evaluation and treatment. School Psychology Review, 13, 171-182.

Reynolds, W. M. (1985). Depression in childhood and adolescence: Diagnosis, assessment, intervention strategies and research. In T. R. Kratochwill (Ed.), Advances in school psychology (Vol. 4, pp. 133-189). Hillsdale, NJ: Lawrence Erlbaum.

Reynolds, W. M. (1986a). A model for the screening and identification of depressed children and adolescents in school settings. Professional School Psychology, 1, 117-129.

Reynolds, W. M. (1986b). Reynolds child depression scale. Odessa, FL: Psychological Assessment Resources. 
Reynolds, W. M. (1986c). Reynolds adolescent depression scale. Odessa, FL: Psychological Assessment Resources.

Reynolds, W. M., \& Coats, K. I. (1986). A comparison of cognitive-behavioral therapy and relaxation training for the treatment of depression in adolescents. Journal of Consulting \& Clinical Psychology, 54, 653-660.

Reynolds, W. M. \& Miller, K. L. (1985). Depression and learned helplessness in mentally retarded and nonmentally retarded adolescents: An initial investigation. Applied Research in Mental Retardation, 6, 295-306.

Rie, H. E. (1966). Depression in childhood: A survey of some pertinent contributions. Journal of the Academy of Child Psychiatry, 5, 635-685.

Rizzo, J. V., \& Zabel, R. H. (1988). Educating children and adolescents with behavioral disorders: An integrative approach. Boston: Allyn \& Bacon.

Rochlin, G. (1959). The loss complex. Journal of the American Psychoanalytic Association, 7, 299-316.

Rutter, M. R. (1986). The developmental psychopathology of depression: Issues and perspectives. In M. R. Rutter, C. E. Izard, \& P. B. Read (Eds.), Depression in young people: Developmental and clinical perspectives (pp. 3-30). New York: Guilford.

Schloss, P. J., Schloss, C. N., \& Harris, L. (1984). A multiple baseline analysis of an interpersonal skills training program for depressed youth. Behavioral Disorders, 9, 182-188.

Seifer, R., Nurcombe, B., Scioli, A., \& Grapentine, W. L. (1989). Is major depressive disorder in childhood a distinct diagnostic entity? Journal of the American Academy of Child and Adolescent Psychiatry, 28, 935-941.

Seligman, M. E. P., \& Peterson, C. (1986). A learned helplessness perspective on childhood depression: Theory and research. In M. Rutter, C. E. Izard, \& P. B. Read (Eds.), Depression in young people: Developmental and clinical perspectives (pp. 223-249). New York: Guilford.

Shure, M. B., \& Spivack, G. (1972). Means-ends thinking, adjustment and social class among elementary school-age children. Journal of Consulting \& Clinical Psychology, 38, 348-353.

Smucker, M. R., Craighead, W. E., Craighead, L. W., \& Green, B. J. (1986). Normative and reliability data for the Children's Depression Inventory. Journal of Abnormal Child Psychology, 14, 25-39.
Spitz, R. A., \& Wolf, K. M. (1946). Anaclitic depression: An inquiry into the genesis of psychiatric conditions in early childhood. Psychoanalytic Study of the Child, 2, 313-341.

Spitzer, R. L., Endicott, J., \& Robins, E. (1978). Research diagnostic criteria: Rationale and reliability. Archives of General Psychiatry, 35, 773-782.

Stark, K. D. (1990). Childhood depression: School-based intervention. New York: Guilford.

Stark, K. D., Kaslow, N. J., \& Reynolds, W. M. (1987). A comparison of the relative efficacy of self-control therapy and a behavioral problem-solving therapy for depression in children. Journal of Abnormal Child Psychology, 15, 91-113.

Stevenson, D. T., \& Romney, D. M. (1984). Depression in learning disabled children. Journal of Learning Disabilities, 17, 579-582.

Strauss, C. C., Last, C. G., Hersen, M., \& Kazdin, A. E. (1988). Association between anxiety and depression in children and adolescents. Journal of Abnormal Child Psychology, 16, 57-68.

Teri, L. (1982a). The use of the Beck Depression Inventory with adolescents. Journal of Abnormal Child Psychology, 10, 277-282.

Teri, L. (1982b). Depression in adolescence: Its relationship to assertion and various aspects of self-image. Journal of Clinical Child Psychology, 11, 101-106.

Thompson, R. J. (1986). Behavior problems in children with developmental and learning disabilities. International Academy of Research in Learning Disabilities Monograph Series, 3, 1-125.

Walker, H. M., \& McConnell, S. R. (1988). Walker-McConnell Scale of Social Competence and School Adjustment. Austin, TX: Pro-Ed.

Walker, H. M., \& Severson, H. H. (1990). Systematic screening for behavior disorders, Longmont, CO: Sopris West.

Wolfe, V. V., Finch, A. J., Jr., Saylor, CA. F., Blount, R. L., Pallymeyer, T. P., \& Carek, D. J. (1987). Negative affectivity in children: A multitrait-multimethod investigation. Journal of Consulting \& Clinical Psychology, 55, 245-250.

\section{PERMISSIONS AND COPYRIGHT}

All rights are reserved. No part of this publication may be reproduced, photocopied, faxed, stored in a retrieval system, or transmitted, in any form or by any means, electronic, mechanical, recording or otherwise, without the prior written permission of the publisher.
Back issues are available for sale. Reproduction requires permission and payment of fees. It is illegal and a violation of Federal copyright law to reproduce this publication without permission. Direct all inquiries to the permissions editor. 


\section{Professional update}

October 10-12, 1991

Council for Learning Disabilities

Annual Conference

Minneapolis, Minnesota

Contact: (913) 492-8755

November 10-12, 1991

Council for Exceptional Children

Conference on At-Risk Children and Youth New Orleans, Louisiana

Contact: CEC, 1920 Association Drive

Reston, VA 22091
November 14-17, 1991

National Early Childhood Conference

on Children with Special Needs

St. Louis, Missouri

Contact: CEC, 1920 Association Drive Reston, VA 22091

November 21-22, 1991

Association for Persons with Severe Handicaps Annual Conference

Washington, D.C.

Contact: TASH, 7010 Roosevelt Way NE, Seattle, WA 98115 